\title{
Intervenciones en preexistencias
}

"Principios y modificaciones de lo real, constituyen la estructura de la creación humana", decía Aldo Rossi en la introducción de su Arquitectura en la ciudad.

Toda creación supone una modificación de lo real, de lo existente, pero no implica un cambio absoluto. Rossi añadia: “(...) es muy evidente que el estudio de la ciudad presenta analogías con el de la lingüística, sobre todo por la complejidad de los procesos de modificación y por las permanencias". En todo cambio, en todo proceso de creación, de evolución, sea en una lengua, en la ciudad o en la arquitectura, hay siempre algo que permanece.

El eje central de este número es precisamente el análisis de esos cambios y de las permanencias. Hablamos de intervenciones en preexistencias, una cuestión que viene debatiéndose desde el clasicismo, sobre la que se ha teorizado en direcciones totalmente opuestas; y lo hacemos a través de la mirada de José Ignacio Linazasoro, un referente en la actualidad, tanto a nivel teórico como práctico al que, precisamente, marcó en sus inicios la citada obra de Rossi.

También lo hacemos a través de siete obras recientes, resultado de siete interpretaciones de la cuestión con ciertos puntos en común.

Al Borde intervienen en una pequeña casa de finales del siglo XIX en La Esperanza (Ecuador), a través de pocas operaciones, pero estratégicas: refuerzan estructuralmente los muros de tierra, sanean las paredes, cambian las puertas y ventanas que estaban en mal estado e igualan el suelo. Por último, aprovechan la necesidad de cambiar la cubierta para en la misma acción resolver las habitaciones. "Una nueva solera amarra los muros y se instalan cerchas de eucalipto cada metro cincuenta y cinco, entre cada cercha se ubica una cama".

Aprovechar la necesidad, una cuestión importante a tener en cuenta.

Un antiguo molino, ejemplo de arquitectura industrial de las primeras décadas del siglo XX, en la zona portuaria de Santa Fe (Argentina), se transforma en Liceo Municipal a través de la demolición de los añadidos sobre la estructura original, surgidos de intervenciones posteriores; sin ocultar las huellas de lo que desaparece. Se devuelve al edificio su espacialidad, se consolida la estructura y se realizan las subdivisiones necesarias para el nuevo uso adoptando un criterio de reversibilidad.

Algo parecido ocurre en el Banco de España con la intervención de Paredes y Pedrosa. Se transforma la planta basamental, poniendo en valor los espacios originarios, se refuerza estructuralmente el muro longitudinal paralelo a esta fachada, se reúsan las ménsulas y barandillas originales y el techo estructural se descubre. Además, se sustituye una antigua escalera por dos ascensores panorámicos generando un nuevo espacio expositivo. 
Elgue y Asociados transforman una vivienda en Asunción otorgándole un doble uso: clínica médica y vivienda. En un ejercicio de intervención más radical que el seguido en los casos anteriores, recurren al ladrillo paraguayo, material clave en las construcciones en el país, pero cambiando su uso: "lo despojamos de su condición pesada para exponerlo como pieza levitante en oposición a la fuerza de gravedad, explorando así modos no tradicionales de construcción cerámica".

En Bogotá, tras los acuerdos de paz con las FARC, una antigua casona de tipología colonial, medianera, abandonada y en ruinas acoge uno de los tres monumentos erigidos con las armas y pertrechos de la guerra. Granada Garcés Arquitectos deciden encapsular las ruinas, generando los nuevos espacios en los vacíos de la antigua construcción, convirtiendo estas en "espacios de arte y contemplación". El monumento se convierte en el suelo de la nueva construcción cubierto por 1.296 adoquines procedentes del metal obtenido tras fundir las armas.

Mendes da Rocha y MMBB Arquitetos actúan sobre unos grandes almacenes, en Sao Paulo, sin gran valor arquitectónico, enfrentándose al reto de reconvertirlos en un espacio con un complicado programa que aúna café, teatro, restaurante, piscina, salas de actividades deportivas, salas de danza, espacios culturales, etc. Para ello realizan una demolición selectiva de la estructura original generando un vacío vertical alrededor del que se estructura el nuevo diseño.

Por último, una pequeña vivienda en la periferia de Salvador de Bahía se convierte en vivienda, galería y espacio educativo. En un proceso inacabado, continuado, iniciado por Federico Calabrese para que avance ya en manos de sus propietarios, como Acervo da Laje, el suburbio en que se ubica, siempre en expansión. Los materiales -el ladrillo- y las técnicas son las mismas usadas en el entorno. Además, incorpora las piezas encontradas por su propietario, "un coleccionista de rastros y restos de la ciudad", un Antonio Pérez brasilero, que en lugar de encontrar obras de arte, recoge recuerdos de su ciudad. Piezas de cerámica, tejas, ladrillos, vidrios rotos...

Aprovechar la necesidad, recuperar los elementos, los espacios valiosos del edificio original, dar un nuevo sentido a materiales y técnicas tradicionales, intervenir sin prejuicios sobre lo que nunca tuvo valor, aportar soluciones flexibles y claves que otros puedan seguir en futuros cambios son solo algunas de las cuestiones que surgen tras reflexionar sobre estas intervenciones. Cualquier avezado observador probablemente encontrará muchas más que puedan serle útiles.

Iniciamos con esta propuesta una nueva etapa en la que número tras número presentaremos, de este mismo modo, a través de la mirada de un Maestro y de una serie de obras, una cuestión sobre la que debatir. 